will be easily seen from the following observations that the exact reverse of this is the case with truly vermicular murements.

If we take the worm as an example, we shall observe that a piece of feather or straw placed under him will be pushed towards the point where the undulations commence. This principle is well shown by taking a piece of india-rubber tubing and plasing it across a smooth table, a weight being placed on one end, and the other moved quickly up and down by the hand so as to produce rapid undulations. If now we place a thin piece of paper under the india-rubber tube we shall see that it will be moved towards the hand, or in a direction opposite to that in which the undulations are trarelling.

If the principle stated above is the correct one, then both Mr. Henry Thompson and Mr. Heath bring forward facts which prove the opposite theory to their own, for it will be seen that on this principle vermicular contractions moving towards the bladder will force a foreign body out at the external urethral orifice.

I consider the expulsion of the few last drops of urine to be a semi-voluntary action produced by the accelerator urinæ; but might it not be possible that the vermicular contractions described are produced by the involuntary muscular fibres surrounding the canal, and be more analogous to the action of the intestines; and that both actions, although in different directions, may produce the same effect-namely, the expulsion of a foreign body by the meatus?

In conclusion, I think there is little doubt that the endoscope is of more benefit in the prevention than the cure of stricture, by bringing under more appropriate treatment those cases of chronic gleet in which, after going the round of injections, balsam, cubebs, \&c., it was generally found necessary to commence the treatment for stricture. At the same time 1 must admit that these cases would have been just as easily cured without the endoscope had the same interest been taken in them. I am, Sir, your obedient servant.

Newton-road, Westbourne-grove, Nov. 1866. Chas. O. Aspray.

\section{HOW TO OBTAIN MEDICAL OFFICERS FOR THE ARMY AND NAVY. \\ To the Editor of THE Lancet.}

SIR, - At the late election of resident-surgeon to St. Bartholomew's Hospital, in this city, there were forty-one candidates. The salary is $£ 200$. In the year 1863 the salary was $£ 120$, and the number of candidates was thirty.

I recommend these facts to the consideration of the War Office and of the Admiralty as showing the easy terms on which civil hospitals can obtain the services of young surgeons, Respecting quality, there was no lack of good men, such as graduates in Medicine, fellows of the College of Surgeons, graduates in Arts, \&c.

How comes it that the public war service is unable to obtain a sufficient supply of candidates?

Instead of answering this question I beg leave to suggest to the authorities the following course :-

Ist. Adhere faithfully to orders in council and warrants.

2nd. Remodel the class of medical officers, constituting them a professional class, and liberating them from relations to other classes.

3rd. Give early retirement and liberal pay.

Rochester, Nov. 1366. I am, Sir, your obedient servant, F. J. Brow: M.D.

\section{MR. F. JORDAN'S OPERATION FOR N EVUS.} To the Editor of THE LANCET.

Sir,-My friends, the secretaries of the Midland Medical Society, have given so exceedingly brief an account of my operation for nevus in the face and orbit that you will, perhaps, kindly permit me to add a very few words of explanation.

Where the skin is not greatly or at all implicated, I make an incision through it, and completely through the nevusdividing it into two halves. Hæmorrhage is easily arrested by pressure at one or more points within or external to the incision; then each half of the tumour is cut out piecemeal with curred scissors. The partially-implicated skin will in time become natural. The cure is effectual and rapid. I have found it to succeed when all other means have failed. The cicatrix of the single incision soon becomes almost imperceptible.

I remain, sir. your obedient servant,

F'rR NEACX JORDAX.

\section{HUNTER IERSES SHARPE.}

COLRT OF QUEEN'S BEXCH, WestuIXster, Nov. 27. (sittings at Nisi Prius, before the Lond ChIEF Justice and a special Jury.)

THIS was an action by Dr. Hunter (whose name has become known by reasun of certain legal proceedings) against the printer and proprietor of the Pall-mall Gazctte for an alleged libel contained in that paper of the loth of November, 1865, entitled "Impostors and Dupes." The article ran thus, the passages declared on being those enclosed in brackets:- "The modern system of easy advertising and the facilities of the penny post have many advantages, but they have also their attendant evils of no little weight. One of these evils is nothing less than a curse upon English society. Occasional exposures in the law courts and the newspapers have long made us familiar with the advertising practices of a certain class of medical impostors, and with the misery they inflict upon their unhappy dupes. And now a series of recent proceedings in the Marylebone Police-office has revealed the existence of ramifications of the detestable system in question for which few ordinary readers will have been prepared. Persons who turn over the pages of the cheap newspapers in search of the curiosities of advertising will have noticed the frequent recurrence of a whole column, purporting to give a consecutive series of extracts from a medical work on consumption by a person signing himself Robert Hunter, M.D. If they have taken the trouble to read its uninviting paragraphs, they will have found that they are a long rigmarole of semi-scientific declamation, professing to expound to the non-professional invalid the causes and symptoms of disease of the lungs, and to prove that nobody knows how to cure it except this same Dr. Hunter, whose method is one of inhalation. On the face of all this there is nothing more than the puffery of the dealers in the various pills, potions, ointments, and liniments, who rejoice in the possession of testimonials from innumerable correspondents who bless the day that they first made the acquaintance of the pill, potion, ointment, or liniment in question, and who are all alike in an unfortunate ignorance of English grammar. That any reputable physician would thus advertise for patients is, of course, out of the question. But although these adver. tisements are free from the mysterious hints and suggestions and the scarcely veiled offensive phraseology of the basest class of medical puffs, one is led to suspect the existence of very serious malpractices by observing the length and the frequency of these recommendations of Dr. Hunter and his inhalations. When a man finds it worth his while to insert a very costly advertisement in several papers, and to go on with it from day to day or week to week, it is clear that his patients must be dupes of a very different class from the simple people who buy pills by the gross and potions by the gallon.] There is no need of the revelations of a police-court to show that the inhaling process means a process for working upon the fears of the ignorant, and for obtaining enormous fees. Men like these advertisers know well that there is one class of society which is specially open to their allurements, and at the same time supplies abundant dupes in such circumstances as to make them quite worth the expense of entrapping. Ladies and gentlemen, and the more wealthy and comfortable class of tradesmen, have, as a rule, their regular family doctors. They dislike doctors' bills as much as any other bills, and it is sometimes hard enough to pay them. But still, until we go further down in the social scale, every man has his own doctor. Then comes an immensely numerous class, whose real education is not much above that of the actual poor, and whose experience of life is confined to a nar. row range. These are the men and women who are the destined victims of the advertising doctors. They read about mucous membranes, and carbonaceous blood, and tubercular deposits, and are impressed with the genius of the gentleman who can thus easily make them familiar with the profoundest secrets of science. If they have anything really the matter with them, their disagreeable sensations are at once intensified; if they have nothing more than a cold in the head, or a tightness in the chest produced by over-indulgence at supper, Dr. Hunter's catalogue of terrific symptoms suggests a mysterious signification to their pains. And when at last the advertisement recommends them to "put their worldly affairs in order, and withdraw their minds from all earthly ties,' for they have only 'a few short months of life' before them-i.e., unless they consult Dr. Hunter, - what else remains but to go the next morning to see the pious, learned, and benevolent 